\title{
Anisotropia de susceptibilidade magnética do plúton Serra da Caiçara, Batólito Águas Belas-Canindé Alagoas, Nordeste do Brasil Anisotropy of magnetic susceptibility of Serra da Caiçara pluton, Águas Belas-Canindé Batholith, Alagoas, Northeast Brazil \\ Charles Henrique Fernandes Sales das Neves ${ }^{1}$ (D), Valderez Pinto Ferreira ${ }^{1}$ (D), Sergio Pacheco Neves ${ }^{1}$ (D), Paulo de Barros Correia ${ }^{1}$ (i) \\ ${ }^{1}$ Universidade Federal de Pernambuco - UFPE, Programa de Pós-Graduação em Geociências, Estrada do Curado, 538, Jardim São Paulo, CEP 50790-108, Recife, PE, BR (charleshfs@hotmail.com; valderez@ufpe.br; serpane@hotlink.com.br; paulobc@ufpe.br)
}

Recebido em 27 de fevereiro de 2018; aceito em 15 de maio de 2019

\begin{abstract}
Resumo
O método de anisotropia de susceptibilidade magnética (ASM) foi aplicado no plúton Serra da Caiçara, que faz parte do batólito Águas Belas-Canindé, Domínio Pernambuco-Alagoas, Província Borborema, Nordeste do Brasil. O plúton tem altos valores de susceptibilidade magnética $(\mathrm{K})\left(90 \%\right.$ dos valores acima de $\left.5 \times 10^{-3} \mathrm{SI}\right)$, típicas da série magnetita granitos. $\mathrm{O}$ grau de anisotropia $(\mathrm{P})$ varia de 1.025 a 1.320. Os maiores valores de $\mathrm{P}$ estão associados às bordas do corpo e possuem correlação positiva com K. O plúton apresenta trama mista, levemente mais oblata, com valores de T entre $-0,822$ e 0,823 . Em geral, as atitudes das foliações e lineações magnéticas são bastante uniformes. As foliações magnéticas têm duas direções preferenciais: NW-SE (dominante, geralmente mergulhando para SW) e NNE-SSW, com mergulho mais variado (geralmente associada aos altos valores de P). As lineações majoritariamente apresentam sentido de caimento SE ou SW. A foliação e a lineação da fácies hornblenda quartzo sienito têm mergulho e caimento moderado, sugerindo se tratar de um corpo tabular, intrusivo concordantemente à foliação regional. A fácies hornblenda quartzo álcali-feldspato sienito (centro do corpo) constitui uma intrusão discordante, com fluxo de SW para NE e mudança de trend para NW. Os dados sugerem que o plúton intrude aproveitando a foliação regional, formada durante a fase de convergência da orogênese Brasiliana. Durante a fase final de cristalização, o plúton foi afetado pela fase transcorrente da tectônica Brasiliana, atuando principalmente nas bordas do corpo e condicionando as foliações e lineações NE-SW.
\end{abstract}

Palavras-chave: Anisotropia de susceptibilidade magnética; Plúton Serra da Caiçara; Batólito Águas Belas-Canindé; Alojamento; Foliação regional.

\begin{abstract}
The Anisotropy of Magnetic Susceptibility (AMS) technique was applied in the Serra da Caiçara pluton, which is part of the Águas Belas-Canindé batholith, Pernambuco-Alagoas Domain of Borborema Province, Northeastern Brazil. The pluton has high values of magnetic susceptibility $(\mathrm{K})\left(90 \%\right.$ of the values above $\left.5 \times 10^{-3} \mathrm{SI}\right)$, typical of granites of the magnetiteseries. The anisotropy degree $(\mathrm{P})$ ranges from 1.025 to 1.320 . The highest $\mathrm{P}$ values are associated with the margins of the body and have a positive correlation with $\mathrm{K}$. The pluton presents a mixed, slightly more oblate, fabric, with $\mathrm{T}$ values between $-0,822$ and 0,823 . In general, magnetic foliations and lineations are fairly uniform and have two preferred directions: NW-SE (dominant, usually plunging to SW) and NNE-SSW, with a more varied plunge (usually associated with high P values). The foliation and lineation of the hornblende quartz syenite facies have low to moderate dip and plunge, respectively, which agrees with the regional fabric. The lineations mostly have SE plunging, indicating the magmatic flow's direction. The hornblende quartz alkali feldspar syenite facies (center of the body) has a discordant fabric, with flow from SW to NE and spreading to NW. The observed structural magnetic structure is consistent with the structural framework of the region, which has two main directions (NE-SW and NW-SE). Data suggest that the pluton intruded taking advantage of the regional foliation formed during the convergent phase of the Brasiliano orogenesis. During the final crystallization phase, the pluton was affected by the transcurrent phase of the Brasiliano event, mainly at the edges of the body, conditioning the NE-SW foliations and lineations.
\end{abstract}

Keywords: Anisotropy of magnetic susceptibility; Plúton Serra da Caiçara; Batholithe Águas Belas-Canindé; Emplacement; Regional foliation. 


\section{INTRODUÇÃO}

A orogênese Brasiliana-Pan-Africana foi responsável pela estruturação atual da Província Borborema (Nordeste do Brasil) (Jardim de Sá e Hachspacher, 1980; Jardim de Sá, 1984; Caby e Arthaud, 1986; Sial, 1986; Brito Neves et al., 1995; Santos, 1996; Santos et al., 2004; Ferreira et al., 1998; Van Schmus et al., 2008). Um dos principais eventos dessa orogênese foi uma abundante granitogênese, que se distribuiu por todos os domínios da província (Ferreira et al., 1998). Estudos aprofundados nessas intrusões podem fornecer informações importantes, desde inferir a composição de níveis mais profundos da crosta e do manto a delimitar e datar eventos de deformação que são bastante importantes durante orogêneses.

A trama interna dos granitos pode registrar a deformação regional, sendo sintectônicos os que têm a trama interna condizente com os das rochas encaixantes, ou com os mecanismos de alojamento (Hutton, 1988; Brown e Solar, 1998; Paterson et al., 1989; Neves et al., 2003; Rosenberg, 2004). Em campo nem sempre é possível observar como se comporta a estruturação interna dos plútons por a maioria aparentar homogeneidade. Com o auxílio da técnica de anisotropia de susceptibilidade magnética (ASM) é possível investigar se a deformação afetou o plúton e como se deu o processo. As medições de ASM fornecem um elipsoide triaxial com eixos K1 $>\mathrm{K} 2>\mathrm{K} 3$, com K1 correspondendo à lineação magnética e K3, ao polo da foliação magnética. Em rochas sem deformação no estado sólido, normalmente a trama magnética corresponde à trama magmática (Ellwood e Whitney, 1980; Bouchez et al., 1990; Borradaile e Henry, 1997; Bouchez, 1997).

Neste trabalho aplicamos o método de ASM, com o estudo petrográfico e de química mineral, no plúton Serra da Caiçara (Silva Filho et al., 2002), uma intrusão neoproterozoica localizada no Domínio Pernambuco-Alagoas da Província Borborema. O trabalho objetivou investigar a trama estrutural interna do plúton e correlacioná-la com os principais eventos deformacionais da Província Borborema. Os resultados apresentados neste trabalho são pioneiros em plútons que compõem o batólito Águas Belas-Canindé. Esses resultados trazem nova perspectiva para o entendimento da construção do batólito, contribuindo para a compreensão da evolução crustal dessa porção do Domínio Pernambuco-Alagoas.

\section{GEOLOGIA REGIONAL}

A Província Borborema (Almeida et al., 1981), localizada no Nordeste do Brasil (Figura 1), com sua respectiva porção situada na África, foi formada durante a convergência e colisão dos crátons Oeste África - São Luiz, São Francisco - Congo e Amazônico durante o Neoproterozoico. $\mathrm{O}$ auge da deformação contracional deu-se por volta de $620 \mathrm{Ma}$ (Van Schmus et al., 2008), em um evento conhecido como orogênese Brasiliana-Pan-Africana (Brito Neves e Cordani, 1991).

Ao longo dos anos, diversos autores, baseando-se em dados litoestratigráficos, feições estruturais, dados geocronológicos e assinaturas geofísicas, propuseram subdivisões para a Província Borborema em subprovíncias e domínios (Santos, 1996; Medeiros e Santos, 1998; Brito Neves et al., 2000; Van Schmus et al., 2008; Neves, 2015). O plúton Serra da Caiçara pertence à Subprovíncia Sul, mais precisamente ao Domínio Pernambuco-Alagoas. Esse domínio é limitado ao norte pela subprovíncia Central e ao oeste e ao sul faz fronteira com os domínios Sergipano e Riacho do Pontal, sendo dividido nas porções oriental e ocidental pela Bacia Tucano-Jatobá (Figura 1A).

Santos (1996) e Medeiros e Santos (1998) reconheceram dois litotipos metamórficos dominantes no Domínio Pernambuco-Alagoas, definindo os complexos Cabrobó e Belém do São Francisco. O complexo Cabrobó é predominantemente supracrustal, composto de granada biotita-gnaisses, com intercalação de quartzito, quartzo-xisto, rochas calcissilicáticas, anfibolitos e ortognaisses migmatizados. O complexo Belém do São Francisco é predominantemente ígneo (migmatitos e ortognaisses que variam em composição de tonalito a granito). Silva et al. (2002) apresentam idade de $2079 \pm 34 \mathrm{Ma}$ (SHRIMP zircão U-Pb) para a cristalização do protólito do ortognaisses Belém do São Francisco e uma idade metamórfica de $655 \pm 7 \mathrm{Ma}$ (SHRIMP zircão U-Pb). Por sua vez, o complexo Cabrobó, datado na localidade tipo (Cruz e Accioly, 2013), na porção oeste do Domínio Pernambuco-Alagoas e na porção sul do PEAL oriental (Neves et al., 2016), apresenta zircões detríticos indicando deposição $<700 \mathrm{Ma}$. Silva Filho et al. $(2002,2014)$ subdividiram o Complexo Cabrobó no PEAL oriental em três sequências (Palmares, Inhapi e Venturosa; Figura 1B) e também determinaram que a idade máxima de deposição é mais jovem que $700 \mathrm{Ma}$. Dessa forma, o Complexo Belém do São Francisco constitui o embasamento do complexo Cabrobó.

A granitogênese que afeta o Domínio PernambucoAlagoas, assim como toda a Província Borborema, pode ser separada em pré-colisional (650 - $640 \mathrm{Ma})$, sin-colisional $(620-600 \mathrm{Ma})$, pós-colisional $(580-550 \mathrm{Ma}) \mathrm{e}$ pós-tectônica ( 550 - $530 \mathrm{Ma}$ ) (Guimarães et al., 2004; Van Schmus et al., 2008; Silva Filho et al., 2016). Grandes batólitos graníticos intrudem os complexos Cabrobó e Belém do São Francisco (Silva Filho et al., 2002). Esses batólitos compreendem uma das unidades litológicas mais 
importantes do Domínio Pernambuco-Alagoas e foram agrupados por Silva Filho et al. (2002) em: Garanhuns, Ipojuca-Atalaia, Correntes-Marimbondo, Águas BelasCanindé e Buíque-Paulo Afonso (Figura 1B). O plúton Serra da Caiçara (Figura 2) é uma das 16 intrusões do batólito Águas Belas-Canindé identificadas por Silva Filho et al. (2002). As fases minerais máficas foram usadas para separar as intrusões do batólito Águas BelasCanindé em quatro grupos, estando o plúton Serra da Caiçara incluído no grupo 1 (anfibólio \pm piroxênio sienitos a sienogranitos).

O batólito Águas Belas-Canindé é separado das rochas metassedimentares de alto grau do Domínio Sergipano pela zona de cisalhamento transpressional Jacaré dos Homens (Oliveira et al., 2006, 2010; Lima et al., 2014;
Silva et al., 2015, 2016) (Figura 1B). A zona de cisalhamento Jacaré dos Homens tem direção ENE-WSW e transporte tectônica para SE. Lima (2013) sugere idade de $642 \pm 3 \mathrm{Ma}$ (U-Pb SHRIMP em zircão) para o início do cisalhamento com base na datação de ortognaisses alojados na zona. Essa idade corresponderia ao início da orogenia Brasiliana, com a formação de uma foliação inicialmente de baixo ângulo regional. Outras zonas de cisalhamento transpressionais expressivas são encontradas no Domínio Pernambuco-Alagoas, como as zonas de cisalhamento Garanhuns e Maravilha, ambas de direção NE-SW (Figura 1B). Em contraste com a zona de cisalhamento Jacaré dos Homens, ambas apresentam transporte tectônico com topo para NW (Silva Filho et al., 2007; Nery, 2016).

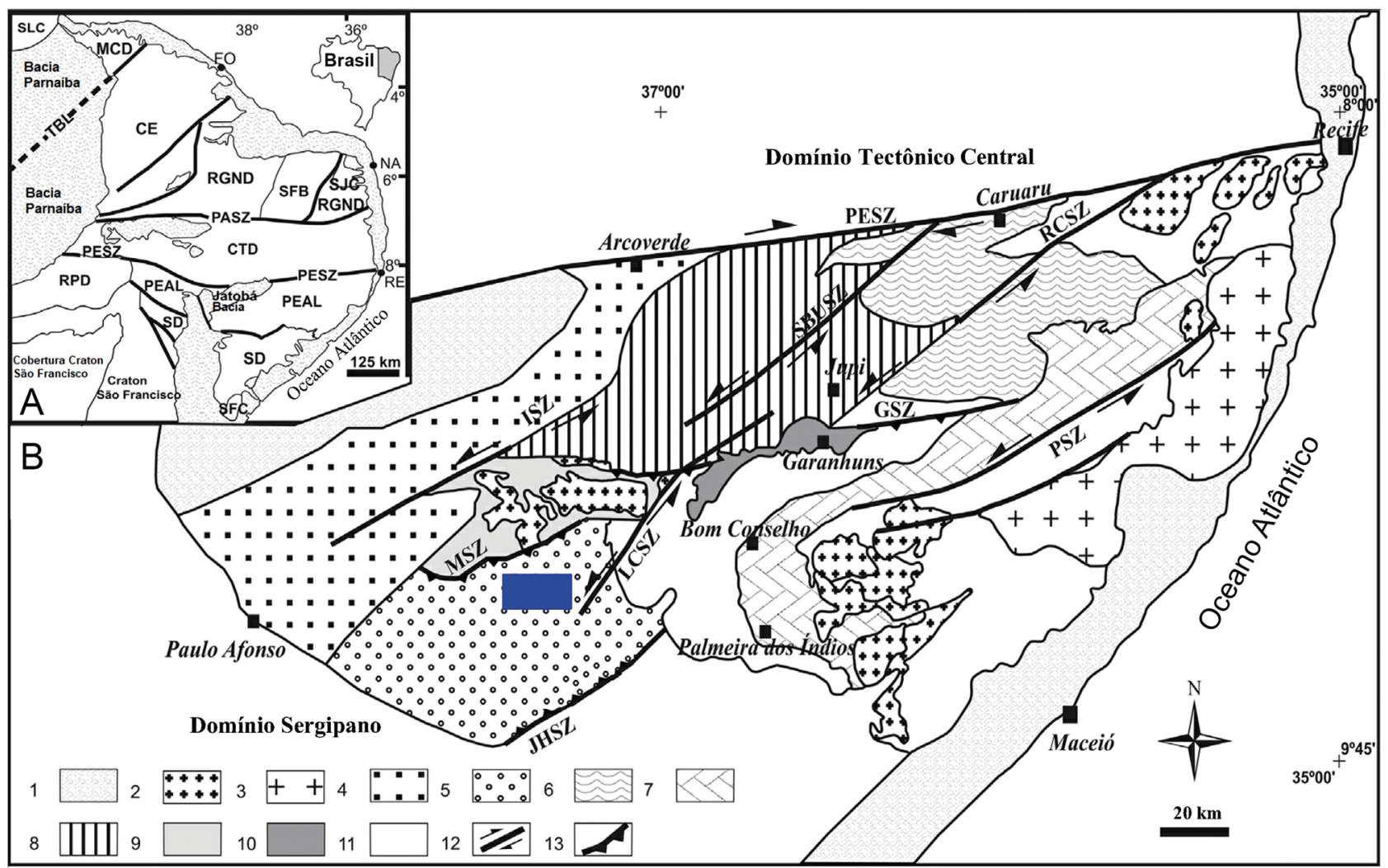

Figura 1. (A) Província Borborema com principais domínios de acordo com Van Schmus et al. (2008): Domínio Ceará CE; Domínio Médio Coreaú - MCD; Domínio Pernambuco-Alagoas - PEAL; Domínio Rio Grande do Norte - RGND (Núcleo Arqueano São José do Campestre - SJC; Faixa de Dobramento Seridó - SFB); Domínio Central - CTD; Domínio Riacho Pontal - RPD; Domínio Sergipano - SD. SFC - Cráton São Francisco. SLC - Cráton São Luís; Zonas de cisalhamento: Patos - PaSZ; Pernambuco - PESZ. Cidades: Fortaleza (FO), Natal (NA), Recife (RE). (B) Mapa geológico simplificado da parte oriental do domínio PEAL (Silva Filho et al., 2010). 1: Cobertura sedimentar palaeozoica; 2: Granitoides Brasilianos; 3: Batólito Ipojuca - Atalaia; 4: Batólito Buíque - Paulo Afonso; 5: Batólito Águas Belas - Canindé; 6: Batólito Garanhuns; 7: Sequência Palmares; 8: Sequência Venturosa; 9: Sequência Inhapi; 10: Quartzito Garanhuns; 11: Complexo Belém do São Francisco; 12: zonas de cisalhamento transcorrentes (PESZ Pernambuco; RCSZ - Rio da Chata; PSZ - Palmares; LCSZ - Limitão-Caetés; ISZ - Itaíba; SBUSZ - São Bento do Una); 13: zonas de cisalhamento transpressivas (GSZ - Garanhuns; MSZ - Maravilha; ZCJH - Jacaré dos Homens). Retângulo em azul marca a área mapeada. 
Posteriormente à fase de baixo ângulo se inicia a fase de transcorrência da orogênese Brasiliana, marcada pela formação de grandes zonas de cisalhamento transcorrentes responsáveis por uma foliação milonítica de alto ângulo. O caráter tardio dessas transcorrências é atestado pelo truncamento, localmente observado, da foliação regional pela foliação milonítica e pelas idades mais jovens registradas em granitos sintranscorrentes (590 - $570 \mathrm{Ma}$; Neves et al., 2008; Silva Filho et al., 2014). As zonas de cisalhamento NE-SW e W-E têm cinemática sinistral e dextral, respectivamente.

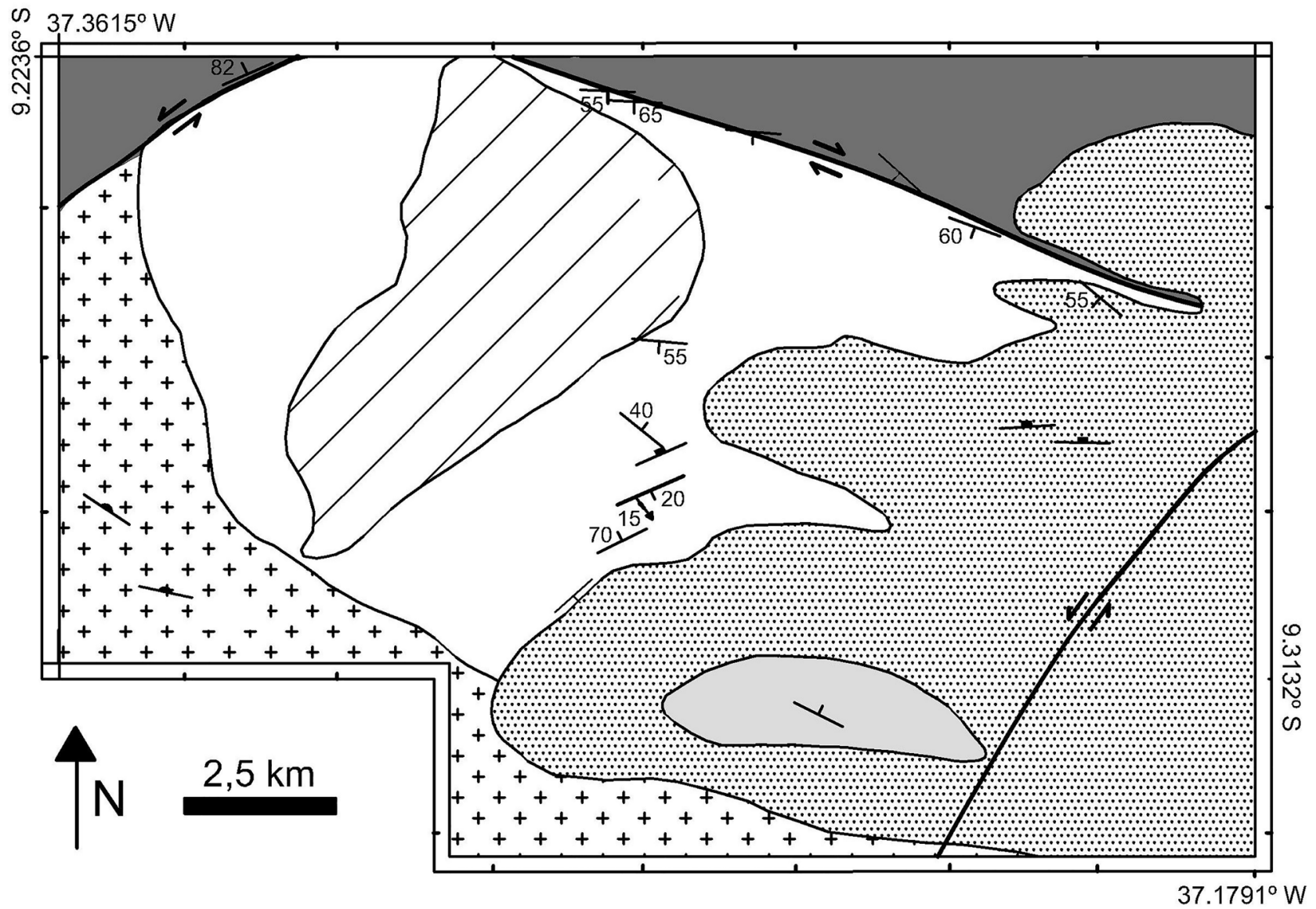

++ Plúton Maravilha:

monzogranitos, com textura porfirítica (K-feldspato com $\sim 5 \mathrm{~cm}$ ). $626 \pm 5 \mathrm{Ma}$ (U-Pb em zircão, SHRIMP) Sales Neves et al. (2018)

Plúton Santana do Ipanema: monzogranitos a sienogranitos, equigranular. $621 \pm 5 \mathrm{Ma}(\mathrm{U}-\mathrm{Pb}$ em zircão, SHRIMP) Sales Neves et al. (2018)

Anfibolito
Plúton Tanquinho: quartzo sienito a quartzo monzonito, textura porfirítica (K-feldspato com $\sim 7 \mathrm{~cm}$ )

Plúton Serra da Caiçara. $616 \pm$ $3 \mathrm{Ma}$ (U-Pb em zircão) Mendes et al. (2009)

Fácies Hornblenda quartzo sienito.

Fácies Hornblenda quartzo alcali-feldspato sienito
Convenções Geológicas

$T_{20}$ Plano de foliação com mergulho medido

Plano de foliação com mergulho indicado

Lineação de estiramento com mergulho medido

- Fratura

Superfície de fluxo magmático com mergulho indicado

$\leftrightharpoons$ Zona de cisalhamento sinistral

$\rightleftharpoons \quad$ Zona de cisalhamento dextral

Figura 2. Mapa geológico de porção do batólito Águas Belas-Canindé, Domínio Pernambuco-Alagoas da Província Borborema, região ao norte de Santana do Ipanema-AL. 


\section{METODOLOGIA}

\section{Amostragem e determinação da anisotropia de susceptibilidade magnética}

Foram obtidos três testemunhos cilíndricos orientados em 50 estações, espaçadas de $\approx 1 \mathrm{~km}$, distribuídas ao longo do plúton. A coleta dos testemunhos foi realizada utilizando uma perfuratriz manual a gasolina. No laboratório, os cilindros foram cortados produzindo um ou dois espécimes (por cilindro), $\operatorname{com} 2,2 \mathrm{~cm}$ de comprimento e 2,5 cm de diâmetro. No total, foram obtidos 253 espécimes. Aanisotropia de susceptibilidade magnética de campo baixo foi determinada utilizando o susceptímetro Kappabridge KLY3 (AGICO), no Laboratório Helmo Rand, Departamento de Geologia da Universidade Federal de Pernambuco, Recife. Cada espécime passou por 15 medições de susceptibilidade em diferentes orientações, de modo a determinar a magnitude e a intensidade do elipsoide de susceptibilidade, sendo os principais eixos $\mathrm{K} 1>\mathrm{K} 2>\mathrm{K} 3$ (K1 corresponde ao eixo máximo do elipsoide ASM, ou lineação magnética, e o eixo mínimo K3 corresponde ao polo da foliação magnética). A susceptibilidade das amostras e os seus principais tensores foram normalizados pelo protocolo de Jelinek (1981).

A média dos parâmetros escalares da ASM para cada estação é apresentada na Tabela 1. A magnitude da susceptibilidade magnética é dada por $\mathrm{K}=1 / 3(\mathrm{~K} 1+\mathrm{K} 2+\mathrm{K} 3)$; a simetria da trama magnética é representada por $\mathrm{T}$ (parâmetro de forma), expressa por $\mathrm{T}=[2(\ln \mathrm{K} 2-\ln \mathrm{K} 3) /(\ln \mathrm{K} 1-\ln \mathrm{K} 3]-1$. $T<0$ corresponde aos elipsoides prolatos $(\mathrm{K} 1>\mathrm{K} 2=\mathrm{K} 3)$, já $T>0$ corresponde aos elipsoides oblatos $(\mathrm{K} 1=\mathrm{K} 2>\mathrm{K} 3)$. $\mathrm{O}$ grau de anisotropia é dado $\mathrm{P}=\mathrm{K} 1 / \mathrm{K} 3$ e pode variar de 1 (isotrópico) a valores mais altos.

\section{Confecção de seções delgadas e análise de microestruturas}

Foram produzidas 21 seções delgadas representativas do plúton Serra da Caiçara, nos mesmos locais em que foram coletados os cilindros para medição da ASM, com o objetivo de caracterizar as microestruturas. Os critérios de Paterson et al. (1989) e Bouchez et al. (1992) foram utilizados para separação das texturas magmáticas e submagmáticas das texturas geradas após a solidificação do magma. Fotomicrografias representativas das principais microestruturas são mostradas nas Figuras $3 \mathrm{e} 4 \mathrm{e}$ a disposição das microestruturas ao longo do plúton é apresentada na Figura 5.

\section{RESULTADOS}

\section{Aspectos de campo e petrográficos}

O plúton Serra da Caiçara (Figura 2) tem uma área de $87 \mathrm{~km}^{2}$ e faz contato intrusivo com os plútons Maravilha, ao sul, e Santana do Ipanema, ao leste. O contato com o plúton Tanquinho, ao norte e ao oeste, é feito por meio de zonas de cisalhamento. O plúton é majoritariamente isotrópico, não sendo possível observar orientações preferenciais, exceto nas bordas NW, SE e N, nas quais a interação com zonas de cisalhamento gera foliações verticalizadas.

Há um marcante aumento na concentração de feldspato potássico no centro do corpo. O plúton é constituído por hornblenda quartzo sienito (fácies dominante) e hornblenda quartzo álcali feldspato sienito (centro do corpo), com coloração creme a castanho, porfiríticos. A fácies central do corpo contém ortoclásio (c. $85 \%$ ), que pode ocorrer como megacristais de até $4 \mathrm{~cm}$ de comprimento, quartzo (c. 5\%) e plagioclásio (c. 5\%) como minerais essenciais. Hornblenda, que chega a atingir $\approx 1 \mathrm{~cm}$ de comprimento, e, por vezes, biotita são as principais fases máficas e totalizam c. $3 \%$ da moda. Titanita euédrica (que chega a atingir $1 \mathrm{~mm}$ ), epidoto, zircão, apatita e magnetita euédrica $(\approx 0,5 \mathrm{~mm}) \mathrm{e}$ anédrica, formam a mineralogia acessória, somando até $2 \%$ da moda. A fácies dominante difere basicamente na concentração modal dos minerais, em que ortoclásio tem $70 \%$ da moda, quartzo (c. 10\%), plagioclásio (c. 10\%), hornblenda + biotita (c. 7\%) e minerais acessórios (c. 3\%). É comum a ocorrência de agregados de hornblenda + biotita + titanita + magnetita + epidoto em ambas as fácies.

Os cristais de magnetita são facilmente observados em lâminas delgadas, variando desde cristais euédricos (Figura 3A) a cristais anédricos, chegando até $1 \mathrm{~mm}$. Ela ocorre como pequenos cristais, incluídos principalmente em hornblenda; formando agregados com hornblenda, biotita, titanita e epidoto (Figura 3B); e como cristais, principalmente euédricos dispersos na rocha.

\section{Microestruturas}

A investigação permitiu a separação de três grupos de microestruturas:

1. Magmática a submagmática: Abrange a maior parte da porção oeste do corpo. É caracterizada pela textura hipidiomórfica granular, com cristais euédricos a subédricos de ortoclásio, geralmente pertítico, e grãos arredondados de quartzo com moderada extinção ondulante (Figura 4A). Inclusões de plagioclásio e quartzo no ortoclásio são comuns. O plagioclásio apresenta geminação polissintética. O mineral máfico dominante é hornblenda euédrica, que chega a atingir $1 \mathrm{~cm}$ de comprimento, e tem pleocroísmo de marrom claro a verde azulado (Figura 4B). A biotita ocorre em quantidade pequena, formada por meio de reação de hornblenda com o magma; raramente ocorre como pequenos cristais isolados. Nessa porção também é possível observar a existência de epidoto magmático (Sial, 1990). Os contatos entre os cristais são retos a levemente curvados; 
Tabela 1. Dados escalares da anisotropia de susceptibilidade magnética.

\begin{tabular}{|c|c|c|c|c|c|c|}
\hline Estação & Espécimes por estação & COORD E & COORD S & $\mathrm{K}\left(10^{-3} \mathrm{SI}\right)$ & $P$ & $T$ \\
\hline $\mathrm{CH} 65$ & 5 & 690148 & 8978662 & 14,24 & 1,119 & $-0,263$ \\
\hline $\mathrm{CH} 66$ & 6 & 688663 & 8973008 & 16,12 & 1,098 & 0,519 \\
\hline $\mathrm{CH} 67$ & 5 & 688205 & 8974430 & 20,13 & 1,040 & 0,438 \\
\hline $\mathrm{CH} 68$ & 4 & 686506 & 8975186 & 11,75 & 1,077 & 0,157 \\
\hline $\mathrm{CH} 69$ & 5 & 685735 & 8975002 & 2,87 & 1,058 & 0,486 \\
\hline $\mathrm{CH} 70$ & 5 & 685785 & 8975744 & 19,73 & 1,097 & 0,330 \\
\hline $\mathrm{CH} 71$ & 6 & 684974 & 8976902 & 22,30 & 1,187 & 0,046 \\
\hline $\mathrm{CH} 72$ & 5 & 683568 & 8977578 & 31,08 & 1,139 & $-0,394$ \\
\hline $\mathrm{CH} 73$ & 5 & 686786 & 8976822 & 17,40 & 1,064 & $-0,300$ \\
\hline $\mathrm{CH} 74$ & 4 & 687073 & 8977842 & 12,59 & 1,075 & $-0,562$ \\
\hline $\mathrm{CH} 75$ & 5 & 687203 & 8979274 & 23,64 & 1,126 & $-0,688$ \\
\hline $\mathrm{CH} 77$ & 5 & 681381 & 8977877 & 27,21 & 1,130 & $-0,750$ \\
\hline $\mathrm{CH} 78$ & 6 & 687924 & 8971034 & 26,78 & 1,262 & $-0,340$ \\
\hline $\mathrm{CH} 79$ & 4 & 686628 & 8972238 & 15,47 & 1,150 & $-0,140$ \\
\hline $\mathrm{CH} 80$ & 6 & 685319 & 8973214 & 13,50 & 1,067 & 0,045 \\
\hline $\mathrm{CH} 81$ & 4 & 684148 & 8973738 & 22,45 & 1,112 & 0,380 \\
\hline $\mathrm{CH} 82$ & 6 & 683057 & 8973844 & 27,54 & 1,081 & 0,268 \\
\hline $\mathrm{CH} 83$ & 5 & 682283 & 8974785 & 4,46 & 1,159 & 0,246 \\
\hline $\mathrm{CH} 85$ & 4 & 681326 & 8977296 & 39,21 & 1,141 & $-0,822$ \\
\hline $\mathrm{CH} 86$ & 5 & 681688 & 8978744 & 29,78 & 1,147 & $-0,355$ \\
\hline $\mathrm{CH} 87$ & 6 & 683467 & 8979608 & 4,90 & 1,181 & 0,402 \\
\hline $\mathrm{CH} 88$ & 6 & 687878 & 8972094 & 3,86 & 1,188 & 0,757 \\
\hline $\mathrm{CH} 89$ & 4 & 687132 & 8973255 & 6,94 & 1,047 & $-0,540$ \\
\hline $\mathrm{CH} 90$ & 5 & 685155 & 8974494 & 16,96 & 1,069 & 0,417 \\
\hline $\mathrm{CH} 91$ & 5 & 683992 & 8975234 & 24,74 & 1,134 & $-0,260$ \\
\hline $\mathrm{CH} 92$ & 4 & 682676 & 8975791 & 27,15 & 1,115 & $-0,745$ \\
\hline $\mathrm{CH} 93$ & 5 & 689558 & 8972314 & 1,26 & 1,178 & 0,117 \\
\hline $\mathrm{CH} 94$ & 5 & 689689 & 8975150 & 22,80 & 1,102 & 0,366 \\
\hline $\mathrm{CH} 95$ & 6 & 692051 & 8976508 & 6,02 & 1,046 & $-0,450$ \\
\hline $\mathrm{CH} 96$ & 6 & 690733 & 8977944 & 23,68 & 1,133 & $-0,042$ \\
\hline $\mathrm{CH} 97$ & 4 & 691167 & 8976927 & 13,76 & 1,078 & $-0,469$ \\
\hline $\mathrm{CH} 98$ & 6 & 684330 & 8972122 & 11,11 & 1,060 & $-0,216$ \\
\hline $\mathrm{CH} 99$ & 5 & 690167 & 8973456 & 7,06 & 1,220 & 0,183 \\
\hline $\mathrm{CH} 100$ & 6 & 690177 & 8975900 & 21,83 & 1,104 & 0,130 \\
\hline $\mathrm{CH} 101$ & 5 & 689303 & 8976632 & 18,96 & 1,162 & 0,298 \\
\hline $\mathrm{CH} 102$ & 4 & 688427 & 8977554 & 15,69 & 1,261 & 0,823 \\
\hline $\mathrm{CH} 103$ & 5 & 687866 & 8978292 & 13,45 & 1,084 & $-0,010$ \\
\hline $\mathrm{CH} 104$ & 5 & 686010 & 8978028 & 14,93 & 1,081 & $-0,096$ \\
\hline $\mathrm{CH} 105$ & 5 & 683909 & 8978486 & 25,72 & 1,123 & $-0,013$ \\
\hline $\mathrm{CH} 106$ & 6 & 687386 & 8976350 & 5,04 & 1,025 & 0,173 \\
\hline
\end{tabular}


Tabela 1. Continuação.

\begin{tabular}{lcccccc}
\hline Estação & Espécimes por estação & COORD E & COORD S & $\mathbf{K}\left(\mathbf{1 0}^{-3} \mathbf{S I}\right)$ & $\mathbf{P}$ & $\mathbf{T}$ \\
\hline $\mathrm{CH} 107$ & 5 & 687966 & 8975620 & 5,01 & 1,047 & 0,418 \\
$\mathrm{CH} 108$ & 6 & 688744 & 8975256 & 20,45 & 1,160 & 0,481 \\
$\mathrm{CH} 109$ & 5 & 690980 & 8975555 & 21,06 & 1,104 & 0,130 \\
$\mathrm{CH} 110$ & 5 & 687788 & 8970256 & 16,56 & 1,320 & 0,479 \\
$\mathrm{CH} 111$ & 6 & 686164 & 8974050 & 4,13 & 1,051 & 0,621 \\
$\mathrm{CH} 112$ & 4 & 694841 & 8976672 & 12,1 & 1,115 & $-0,260$ \\
$\mathrm{CH} 113$ & 5 & 692457 & 8977894 & 20,01 & 1,116 & $-0,300$ \\
$\mathrm{CH} 114$ & 5 & 693685 & 8976182 & 10 & 1,100 & $-0,090$ \\
$\mathrm{CH} 115$ & 4 & 685895 & 8970825 & 25,01 & 1,200 & $-0,300$ \\
$\mathrm{CH} 116$ & 5 & 686047 & 8980457 & 24,5 & 1,220 & $-0,260$ \\
\hline
\end{tabular}
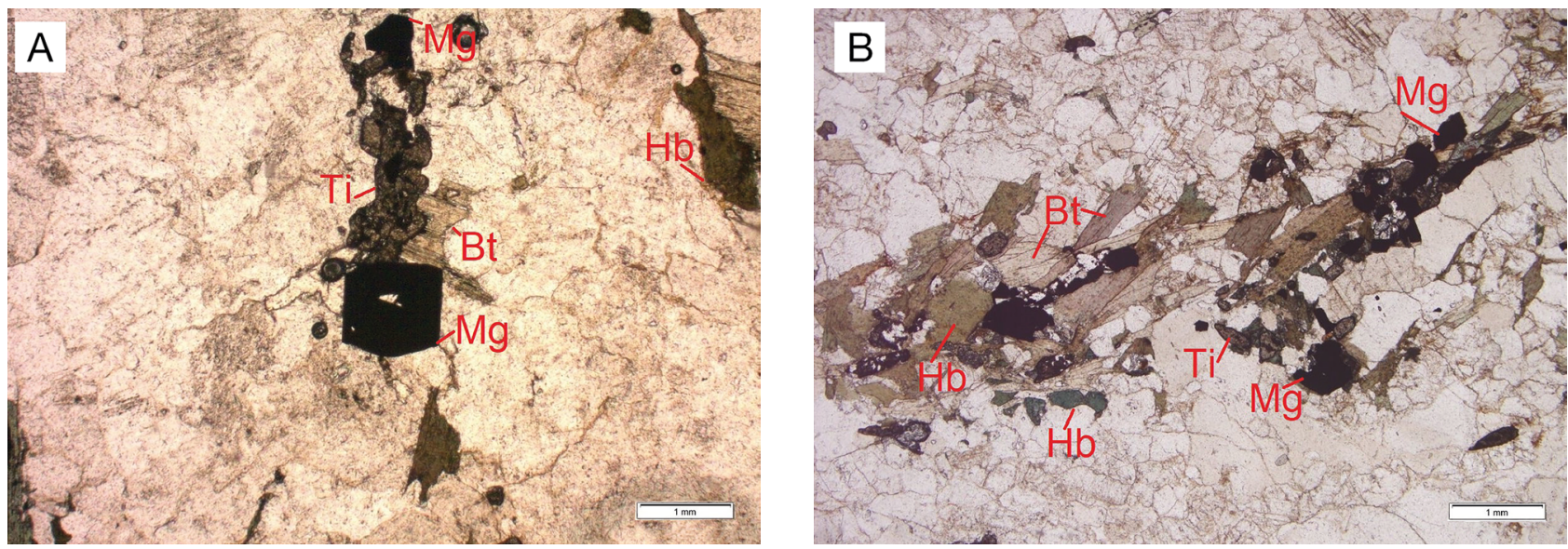

$\mathrm{Hb}$ : hornblenda; Bt: biotita; Mg: magnetita; Ti: titanita.

Figura 3. (A) Grande cristal de magnetita euédrico, pertencente à microestrutura magmática. (B) Cristais de magnetita orientados paralelamente à foliação. Polarizadores paralelos.

2. Recristalização moderada: Abrange a porção central do plúton. É marcada pela diminuição da quantidade e do tamanho dos minerais máficos, com as mesmas quantidades modais, aproximadamente, de hornblenda e biotita. Os cristais de quartzo são equidimensionais a levemente alongados. Estes últimos apresentam contatos irregulares, embaiados, evidenciando recristalização por migração de limites de grãos (Figura 4C). Alguns grãos de feldspato potássico apresentam recristalização nas bordas e pertitas sigmoidais. Por vezes, os cristais de biotita encontram-se dobrados (Figura 4D);

3. Alto grau de recristalização: Concentra-se principalmente nas porções sudeste e noroeste do corpo. É caracterizado por diminuição do tamanho do grão e pela orientação preferencial dos minerais máficos, sendo a biotita o principal representante. Os cristais de feldspato potássico encontram-se fraturados, com contatos irregulares, denteados e serrilhados, sugerindo recristalização dinâmica por bulging, e, em alguns casos, mostram extinção ondulante (Figura 4E); pertitas em chamas ocorrem frequentemente. Quartzo ocorre como grãos alongados apresentando bandas de deformação e contatos interlobados, evidenciando recristalização dinâmica por migração de limites de grãos e localmente bulging (Figura 4F). Plagioclásio também mostra recristalização nas bordas. É possível observar biotita recristalizada preenchendo espaços entre os grãos de feldspato potássico e quartzo.

\section{Dados escalares}

Os valores para a susceptibilidade magnética $(\mathrm{K})$ variam entre $1,26 \times 10^{-3}$ SI e $39,21 \times 10^{-3}$ SI. De acordo com Rochette 

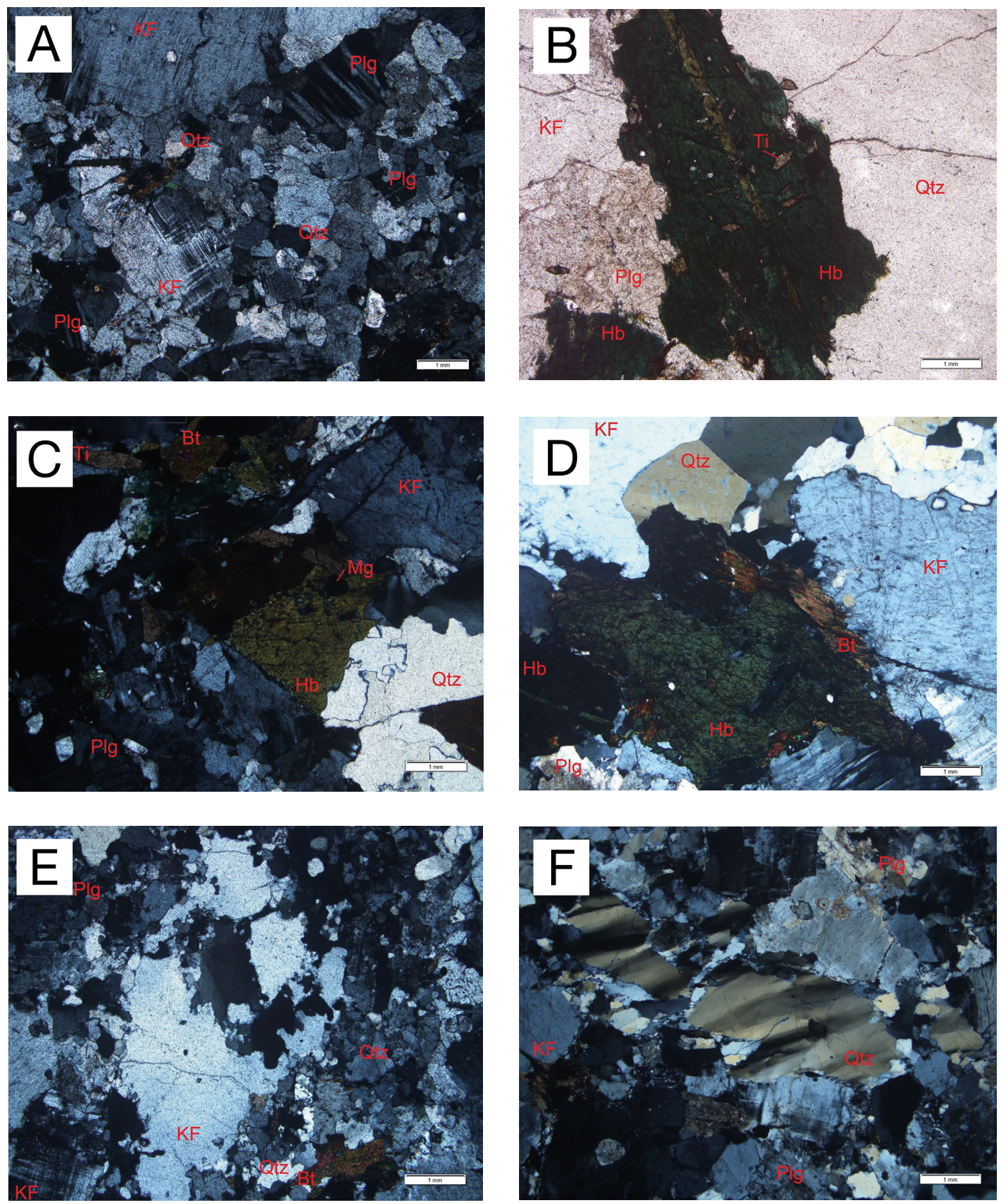

KF: feldspato potássico; Plg: plagioclásio; Qtz: quartzo; Hb: hornblenda; Bt: biotita; Mg: magnetita; Ti: titanita.

Figura 4. Microestruturas do plúton Serra da Caiçara. A e B, representam o domínio Magmático. (A) Imagem enfatizando os contatos entre os minerais (retos a levemente arredondados) tipos do estado magmático (polarizadores cruzados). (B) Cristal de hornblenda zonado, com pleocroismo em tons de verde característico, destaque para o tamanho do cristal, $\approx 10 \mathrm{~mm}$ (polarizadores paralelos). C e D representam o domínio Recristalização Moderada. (C) Cristal de feldspato potássico com pertitas sigmoidais (polarizador cruzado). (D) Recristalização nas bordas do feldspato potássico, biotita levemente dobrada na borda de um cristal de hornblenda (polarizador cruzado). E e F representam o domínio Alto Grau de Recristalização. (E) Feldspatos com contatos irregulares, denteados e serrilhados, sugerindo recristalização dinâmica por bulging e abundância de mirmequitas (polarizadores cruzados). (F) Quartzo com bandas de deformação e apresentando recristalização (polarizadores cruzados). 
(1987) e Rochette et al. (1992), 0,5 × 10-3 é o valor máximo paramagnético de um sienito. Portanto, os valores elevados de K, típicos da série dos magnetita granitos (Ishihara, 1977), com $90 \%$ dos valores acima de $5 \times 10^{-3} \mathrm{SI}$, mostram que o plúton Serra da Caiçara é ferromagnético. Em mapas de contorno de K (Figura 6A) se observa a existência de dois corredores de alta susceptibilidade magnética, na direção NE-SW. Possivelmente, esses corredores refletem o condicionamento tectônico resultante do regime transcorrente, visto que têm aproximadamente a mesma direção das zonas de cisalhamento transcorrentes de orientação NE-SW presentes na região.

No gráfico $\mathrm{P} \times \mathrm{K}$ (Figura $6 \mathrm{~B}$ ) se observa correlação positiva entre esses dois parâmetros. Também é possível observar que as amostras se separam em dois trends. $\mathrm{O}$ trend com maiores valores de $\mathrm{P}$ se encontram nas bordas do corpo. Essa correlação sugere que $\mathrm{P}$ é controlado pela composição da rocha (Archanjo et al., 1994), principalmente de cristais de magnetita, que, por vezes, são concentrados acompanhando as direções das estruturas presentes (Figura 3B). O grau de anisotropia $(\mathrm{P})$ varia de 1.025 a 1.320. Os maiores valores de $\mathrm{P}$ estão associados com as bordas do corpo (Figura 6C).

Quanto à forma do elipsoide de ASM, o plúton Serra da Caiçara apresenta valores de $\mathrm{T}$ variando de $-0,822$ a 0,823 . Não foram observadas correlações entre T e K (Figura 6D) ou $\mathrm{T}$ e $\mathrm{P}$, indicando possível obtenção da forma ainda durante a colocação do magma. É possível observar predomínio de elipsoides oblatos na porção central do corpo e elipsoides prolatos nos bordos (Figura 6E), indicando predomínio de trama linear na borda. No gráfico de correlação de $\mathrm{T} \times \mathrm{K}$ (Figura 6F), é possível observar leve predomínio de elipsoides oblatos.

\section{Dados direcionais}

Em geral, tanto a foliação magnética quanto a lineação magnética são bastante uniformes ao longo do plúton (Figura 7). As foliações magnéticas têm duas direções preferenciais: NW-SE, dominante, geralmente mergulhando para SW, e NNE-SSW, com mergulho mais variado. Trinta estações apresentaram foliação com direção NW-SE, com mergulho médio de $50^{\circ}$, distribuídas uniformemente ao longo do plúton. Vinte estações apresentaram direção NNE-SSW, com mergulho médio de $60^{\circ}$, as quais se concentram nas porções NW e SE do plúton (Figura 7A).

As lineações magnéticas (Figura 7B) apresentam caimento baixo, com média geral de $\approx 30^{\circ}$. Quando associadas às foliações de direção NW-SE, têm sentido de caimento preferencial entre SSW e SSE. Quando associadas às foliações de direção NNE-SSW, apresentam sentido de caimento tanto para NE como para SW.

A trama magnética NNE-SSW coincide com os altos valores de $\mathrm{P}$, que se encontram principalmente nas bordas NW e SE do plúton. Essa direção é condizente com a da zona de cisalhamento sinistral que bordeja a porção noroeste do corpo (Figura 2). As foliações com direção NW-SE são concordantes com as direções medidas em campo, próximas aos contatos com os plútons Tanquinho e Maravilha (Figura 2).

\section{DISCUSSÃO}

\section{Mineralogia magnética e origem da estrutura magnética}

A alta susceptibilidade magnética apresentada no plúton Serra da Caiçara, associada com análises petrográficas (Figura 3),

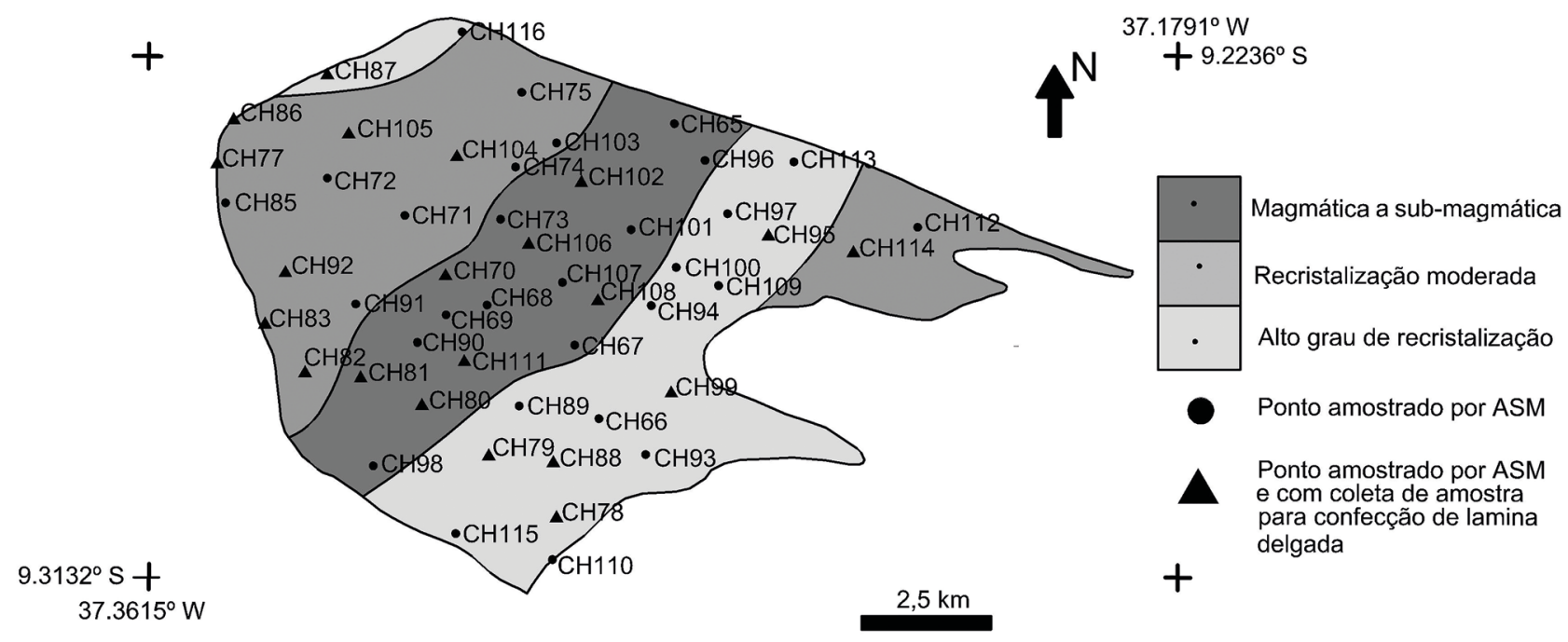

Figura 5. Mapa do plúton Serra da Caiçara mostrando a localização dos pontos amostrados para anisotropia de susceptibilidade magnética (ASM), das seções delgadas estudadas e com as separações dos campos microestruturais. 
indica que o mineral responsável pela susceptibilidade é a magnetita. $\mathrm{O}$ aumento ou a diminuição na susceptibilidade magnética estão diretamente ligados ao teor de magnetita, ou seja, quanto maior o teor, maior a susceptibilidade magnética. A orientação de grãos de magnetita provavelmente está controlada pela orientação dos silicatos (Hrouda e Lanza, 1989; Archanjo et al., 1995), como observado na Figura 3B. Em uma das estações, na porção centro-noroeste do plúton, foi possível a medição da foliação magmática com bússola. Nesse ponto, a foliação magmática é marcada por orientação dos cristais de hornblenda, que formam um bandamento incipiente marcado pela alternância de faixas ricas em feldspato potássico e hornblenda. A atitude da foliação magnética, obtida por ASM, é bastante próxima da atitude da foliação magmática medida em campo, indicando que as tramas magnéticas e magmáticas são coaxiais.

Nas bordas do corpo em que se observa aumento do grau de anisotropia (P) e predomina a microestrutura de Alto Grau de Recristalização, a magnetita ocorre em maior quantidade e está inserida na foliação da rocha (Figura 3B),
A

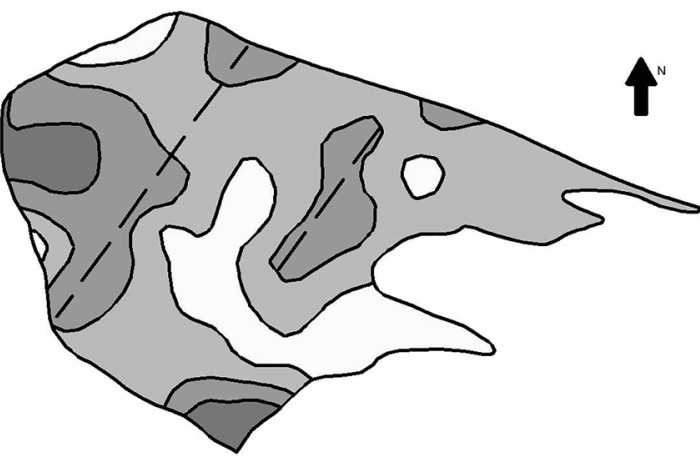

C

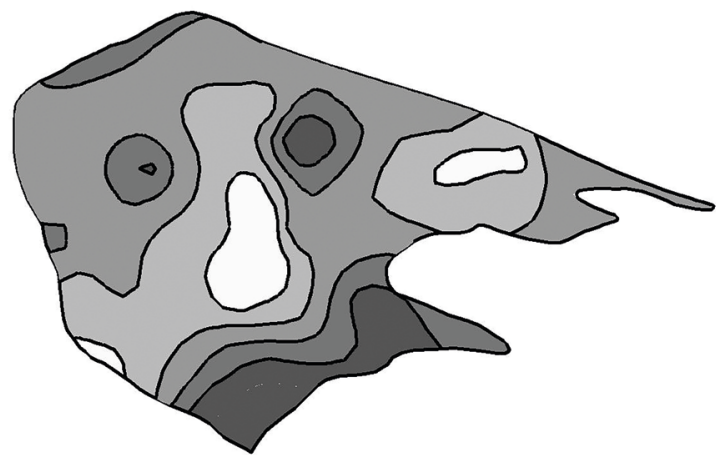

$\mathrm{E}$

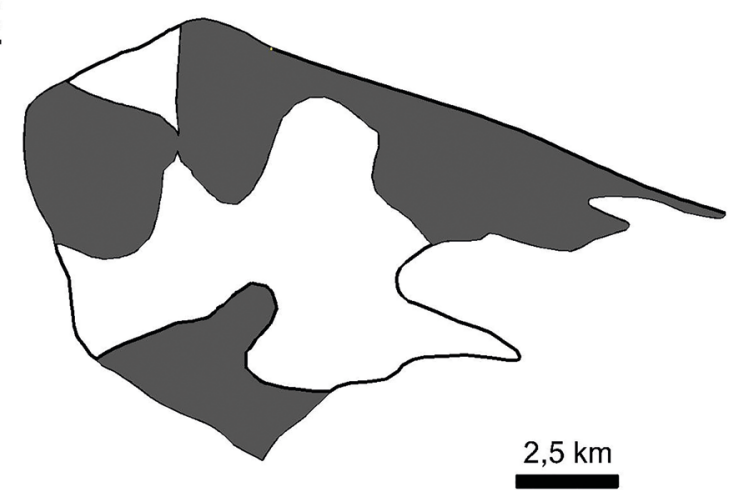

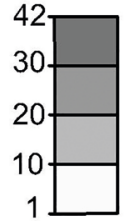

$\mathrm{K}\left(10^{-3}\right) \mathrm{SI}$
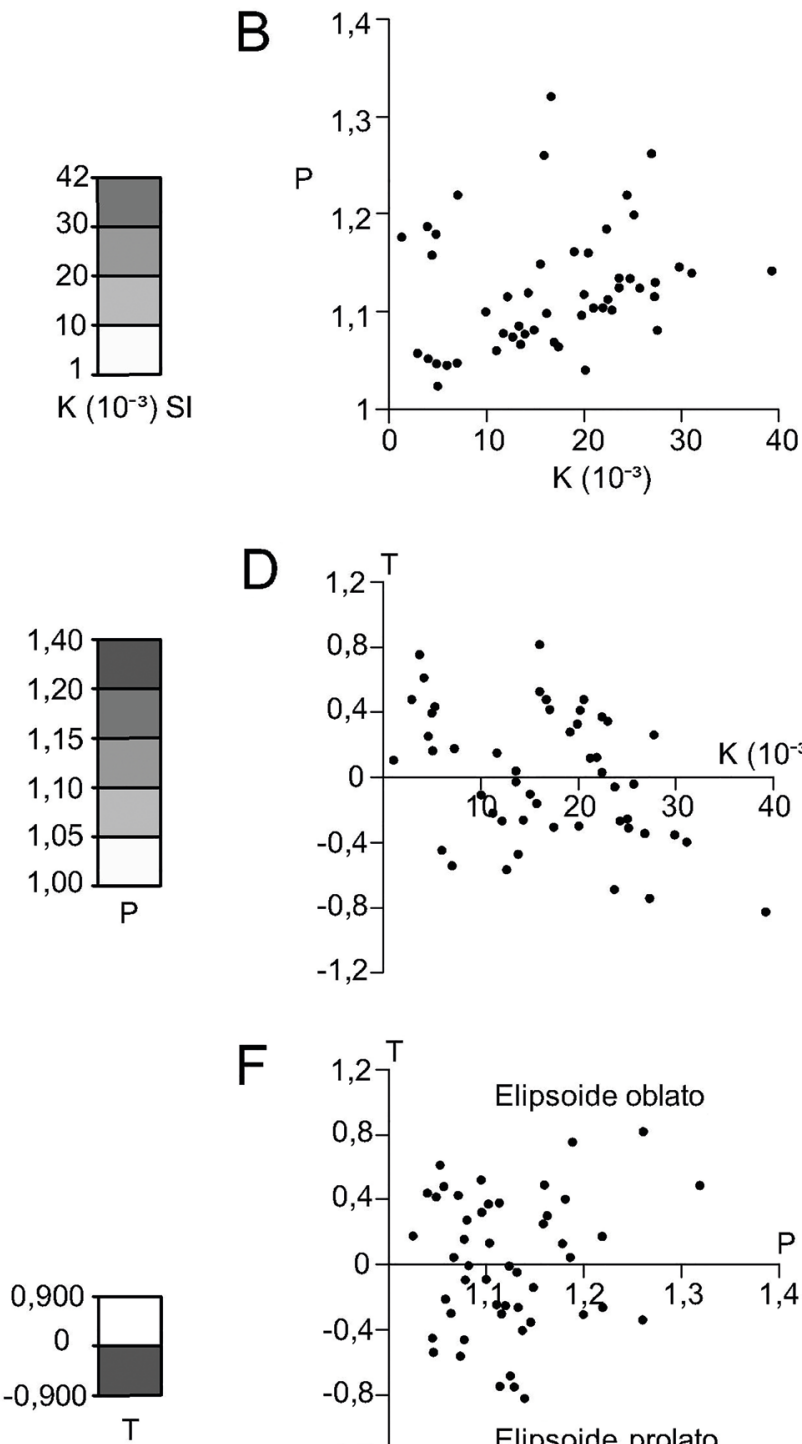

D

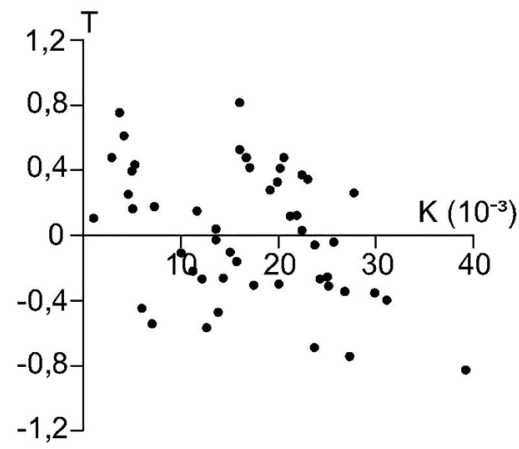

$\mathrm{F}$

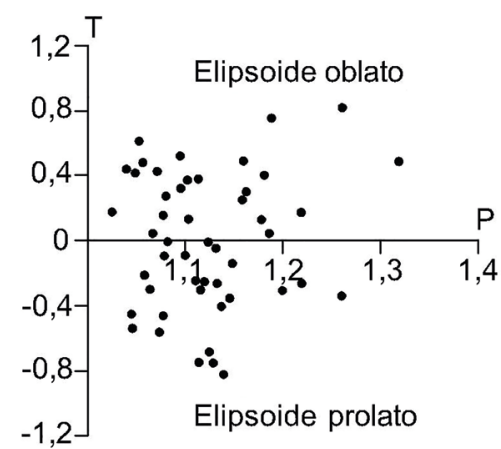

Figura 6. (A) Magnitude da Susceptibilidade Magnética [K], linhas tracejadas enfatizando os corredores de alta susceptibilidade magnética. (B) Grau de anisotropia [P] vs. magnitude da susceptibilidade magnética [K]. (C) Distribuição do grau de anisotropia [P]. (D) Parâmetro de forma [T] vs. [K]. (E) distribuição do parâmetro de forma [T]. (F) [T] vs. [P]. A, C e E apresentam o mapa do plúton Serra da Caiçara. A interpolação dos dados apresentadas em A, C e E foi realizada utilizando o software Oasis Montaj. 
que é caracterizada principalmente pela orientação preferencial de biotita. Dessa forma, justifica-se o aumento de $\mathrm{P}$ e a correlação de aumento entre $\mathrm{P}$ e $\mathrm{K}$, observados nas Figuras $6 \mathrm{~B}$ e $6 \mathrm{C}$, respectivamente.

A alta susceptibilidade magnética e a presença de epidoto magmático observado na microestrutura Magmática indicam que o plúton Serra da Caiçara cristalizou em condições de alta fugacidade de O2 (Ferreira et al., 2011). De acordo com Wones (1989), a presença da associação mineral quartzo + titanita + magnetita sugere que a fugacidade de O2 seja acima do tampão QFM, favorável à presença de epidoto magmático (Sial, 1990).

\section{Mecanismos de alojamento e efeitos da tectônica regional sobre a estruturação do plúton}

Diversos autores relacionam as intrusões com idades em torno de 620 Ma no Domínio Pernambuco-Alagoas com o desenvolvimento da foliação regional, inicialmente de baixo

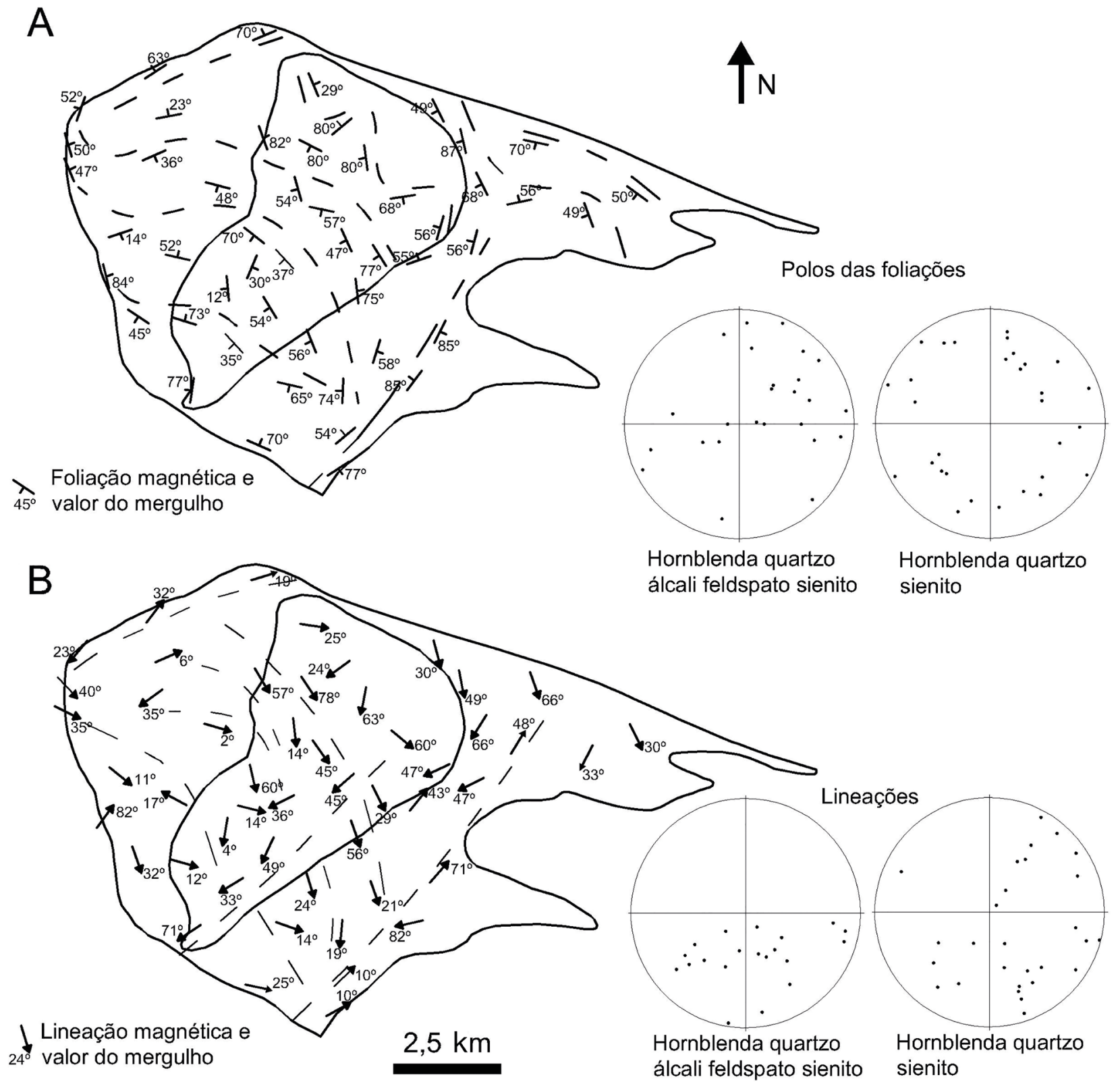

Figura 7. Mapa de foliações (A) e lineações (B) magnéticas do plúton Serra da Caiçara. Linhas tracejadas representam isolinhas que marcam a estruturação interna interpretada do corpo. 
ângulo, existente nesse domínio (Guimarães et al., 2004; Neves et al., 2012; Silva et al., 2015, 2016). Essa estruturação foi gerada durante a fase contracional da orogênese Brasiliana, tendo início por volta de $630-640 \mathrm{Ma}$ (Guimarães et al., 2004; Neves et al., 2005a, 2005b; Neves et al., 2015). O plúton Serra da Caiçara tem idade de cristalização, U-Pb em zircão, de $616 \pm 3 \mathrm{Ma}$ (Mendes et al., 2009), indicando ter intrudido 15 - 25 Ma após o início da deformação contracional, aproveitando uma foliação regional já desenvolvida.

Os dados sugerem que as duas fácies do plúton Serra da Caiçara passaram por processos de intrusão diferentes. A fácies hornblenda quartzo sienito, dominante no plúton, tem predominância de foliações e lineações magnéticas com ângulo baixo a moderado. O parâmetro de forma tem leve predomínio dos elipsoides oblatos. Essas características sugerem que a intrusão do plúton se deu inicialmente de forma concordante à foliação regional (formada por tectônica de empurrão; Figura 8A). Essa hipótese é suportada por um afloramento em que foi encontrado um sill dessa fácies intrudindo metagranitoides (Figura 8B). O fluxo magmático foi de SE para NW, visto que o caimento das lineações mais frequente é para SE. Na fácies hornblenda quartzo álcali-feldspato sienito, que aflora no centro do corpo, o traço da foliação aparenta truncar o contato com a fácies dominante, apontando para uma intrusão discordante (Figuras 8C). O caimento das lineações sugere que o fluxo do magma se deu de SW para NE e teve espalhamento para NNW.

As bordas do plúton, em que aparecem as microestruturas Alto Grau de Recristalização, já estariam consolidadas quando ele foi afetado pela tectônica transcorrente. Essa tectônica atuou no plúton, principalmente, condicionando as foliações e lineações magnéticas de direção NE-SW, paralelas às grandes zonas de cisalhamento sinistrais (marcadas por foliação milonítica) presentes no Domínio PernambucoAlagoas e que limitam a porção NW do plúton. O plúton Serra da Caiçara registra, portanto, a estruturação gerada durante a colocação magmática bem como a estruturação tectônica posterior. É ainda inferido um dobramento na parte norte do plúton (Figura 7A) com base na disposição dos planos de foliação obtidos com ASM, o qual também seria associado à tectônica transcorrente.
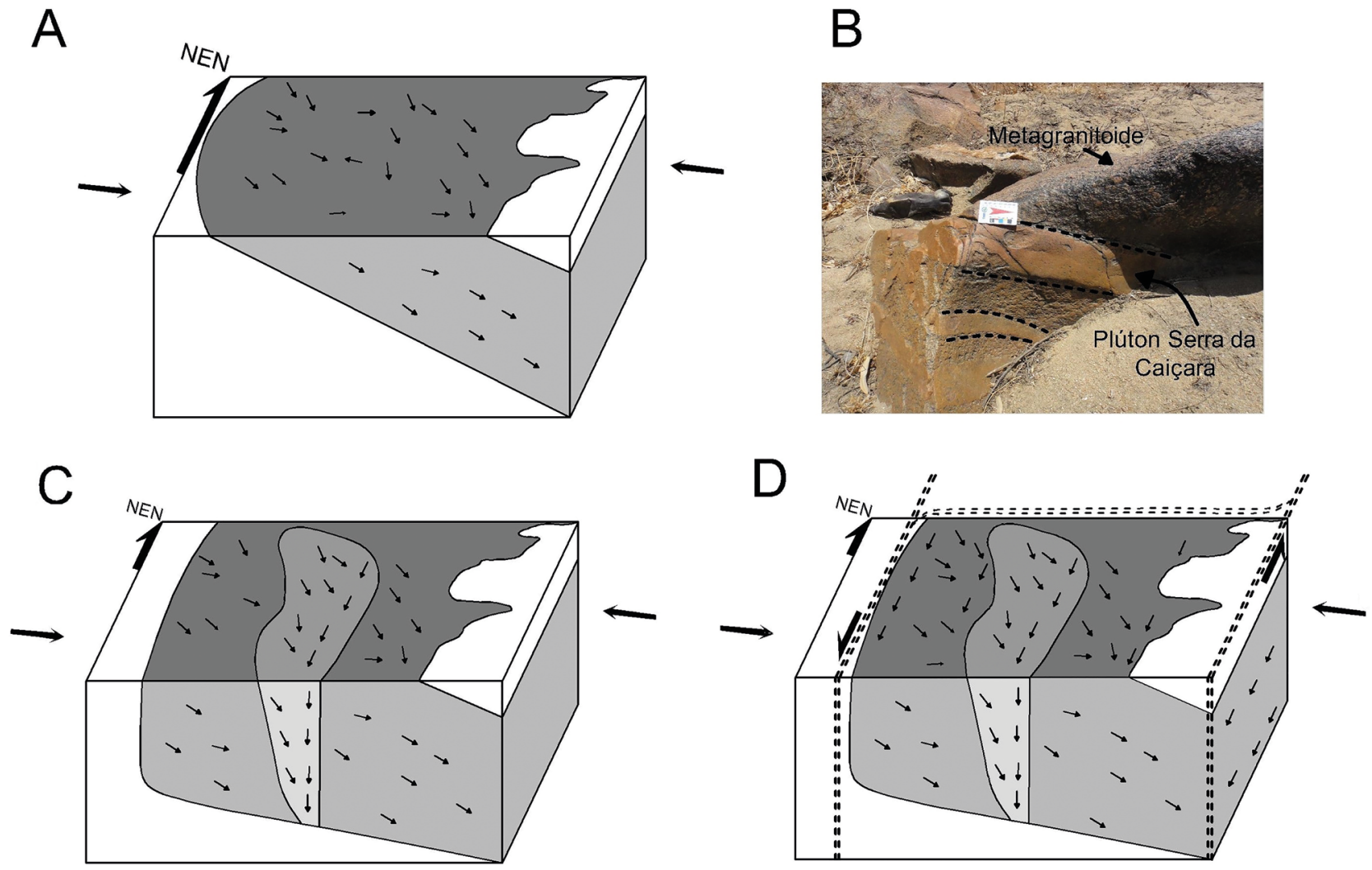

Figura 8. Modelo sugerido para o alojamento do plúton Serra da Caiçara. (A) Intrusão da fácies hornblenda quartzo sienito de forma concordante à foliação regional. (B) Análogo encontrado em campo, mostrando um sill relacionado ao plúton Serra da Caiçara intrudindo metagranitoide. (C) Intrusão da fácies hornblenda álcali-feldspato sienito. (D) Efeito da deformação no plúton, geração das zonas de cisalhamento sinistrais de direção NE-SW, marcada por foliações de alto ângulo (miloníticas; linhas tracejadas), e reorientação de foliações e lineações para esta direção. 


\section{CONCLUSÃO}

A colocação do plúton Serra da Caiçara (616 Ma) ocorreu em dois estágios: o primeiro é caracterizado pela intrusão da fácies dominante de forma concordante com a foliação regional; o segundo é marcado pela intrusão discordante da fácies aflorante no centro do corpo. A tectônica transcorrente afeta o plúton em um estágio tardio de cristalização e atua principalmente nas suas bordas.

O modelo de alojamento proposto para o plúton Serra da Caiçara, que teve como base a técnica de ASM, descreve bem a relação das intrusões com idade por volta de $620 \mathrm{Ma}$ com a foliação regional resultante da orogênese Brasiliana, sendo a primeira modelagem do tipo para plútons do batólito Águas Belas Canindé, podendo ser aplicada a outras intrusões com as mesmas características.

\section{REFERÊNCIAS}

Almeida, F. F. M., Hasui, Y., Brito Neves, B. B., Fuck, R. A. (1981). Brazilian structural provinces: an introduction. Earth Sciences Reviews, 17(1-2), 1-29. https://doi. org/10.1016/0012-8252(81)90003-9

Archanjo, C. J., Bouchez, J. L., Corsini, M., Vauchez, A. (1994). The Pombal granite pluton: magnetic fabric. Emplacement and relationships with the Brasiliano strike slip setting of NE Brazil (Paraiba State). Journal of Structural Geology, 16(3), 323-335. https://doi.org/10.1016/0191-8141(94)90038-8

Archanjo, C. J., Launeau, P., Bouchez, J. L. (1995). Magnetic fabric vs. magnetite and biotite shape fabrics of the magnetitebearing granite pluton of Gameleiras (Northeast Brazil). Physics of the Earth and Planetary Interiors, 89(1-2), 63-75. https://doi.org/10.1016/0031-9201(94)02997-P

Borradaile, G. J., Henry, B. (1997). Tectonic applications of magnetic susceptibility and its anisotropy. EarthScience Reviews, 42(1-2), 49-93. https://doi.org/10.1016/ S0012-8252(96)00044-X

Bouchez, J. L., Gleizes, G., Djouadi, T., Rocbette, P. (1990). Microstructure and magnetic susceptibility applied to emplacement kinematics of granites: The example of the Foix pluton (French Pyrenees). Tectonophysics, 184, 157171. https://doi.org/10.1016/0040-1951(90)90051-9

Bouchez, J. L. (1997). Granite is never isotropic: an introduction to AMS studies of granitic rocks. In: J. L. Bouchez, D. H. W. Hutton, W. E. Stephens (Eds.), Granite: From Segregation of Melt to Emplacement Fabrics. Kluwer Academic Publishers. p. 95-112. https://doi.org/10.1007/978-94-017-1717-5_6
Bouchez, J. L., Delas, C., Gleizes, G., Ntdelec, A., Cuney, M. (1992). Submagmatic microfractures in granites. Geology, 20(1), 35-38. https://doi. org/10.1130/0091-7613(1992)020<0035:SMIG $>2.3 . \mathrm{CO} ; 2$

Brito Neves, B. B., Cordani, U. G. (1991). Tectonic evolution of South America during the Late Proterozoic. Precambrian Research, 53(1-2), 23-40. https://doi. org/10.1016/0301-9268(91)90004-T

Brito Neves, B. B., Santos, E. J., Van Schmus, W. R. (2000). Tectonic history of the Borborema Province, Northeastern Brazil. In: U. Cordani, E. J. Milani, A. Thomaz Filho, D. A. Campos (Eds.), Tectonic evolution of South America. 31st International Geological Congress, Rio de Janeiro, 151-182.

Brito Neves, B. B., Van Schmus, W. R., Santos, E. J., Campos Neto, M. C., Kozuch, M. (1995). O Evento Cariris Velhos na Província Borborema: Integração de Dados, Implicações e Perspectivas. Revista Brasileira de Geociências, 25(4), 279-296.

Brown, M., Solar, G. S. (1998). Granite ascent and emplacement during contractional deformation in convergent orogens. Journal of Structural Geology, 20(9-10), 1365-1393. https://doi.org/10.1016/S0191-8141(98)00074-1

Caby, R., Arthaud, M. (1986). Major Precambrian nappes of the Brazilian Belt, Ceará, northeast Brazil. Geology, 14(10), 871874. https://doi.org/10.1130/0091-7613(1986)14<871:MPN OTB $>2.0 . \mathrm{CO} ; 2$

Cruz, R. F., Accioly, A. C. A. (2013). Petrografia, geoquímica e idade U-Pb do Ortognaisse Rocinha, no domínio Pernambuco-Alagoas e W da Província Borborema. Estudos Geológicos, 23, 3-27.

Ellwood, B. B., Whitney, J. A. (1980). Magnetic fabric of the Elberton granite, Northeast Georgia. Journal of Geophysical Research, 85(B3), 1481-1486. https://doi.org/10.1029/ JB085iB03p01481

Ferreira, V. P., Sial, A. N., Jardim de Sá, E. F. (1998). Geochemical and isotopic signatures of the Proterozoic granitoids in terranes of the Borborema Province, northeastern Brazil. Journal South American Earth Science, 11(5), 439455. https://doi.org/10.1016/S0895-9811(98)00027-3

Ferreira, V. P., Sial, A. N., Pimentel, M. M., Armstrong, R., Spicuzza, M. J., Guimarães, I. P., Silva Filho, A. F. (2011). Contrasting sources and P-T crystallization conditions of epidote-bearing granitic rocks, northeastern Brazil: $\mathrm{O}, \mathrm{Sr}$, and $\mathrm{Nd}$ isotopes. Lithos, 121, 189-201. https://doi.org/10.1016/j. lithos.2010.11.002 
Guimarães, I. P., Silva Filho, A. F., Almeida, C. N., Van Schmus, W. R., Araújo, J. M. M., Melo, S. C., Melo, E. B. (2004). Brasiliano (Pan-African) granitic magmatism in the Pajeu-Paraiba belt, northeast Brazil: an isotopic and geochronological approach. Precambrian Research, 135(1-2), 23-53. https://doi.org/10.1016/j. precamres.2004.07.004

Hrouda, F., Lanza, R. (1989). Magnetic fabric in the Biella and Traversella stocks (Periadriatic line): implications for the model of emplacement. Physics of Earth and Planetary Interior, 56(3-4), 337-348. https://doi. org/10.1016/0031-9201(89)90168-4

Hutton, D. H. W. (1988). Granite emplacement mechanisms and the tectonic controls: inferences from deformation studies. Earth and Environmental Science, 79(2-3), 245-255. https://doi.org/10.1017/ S0263593300014255

Ishihara, S. (1977). The magnetite-series and ilmeniteseries granitic rocks. Mining Geology, 27(145), 293-305. https://doi.org/10.11456/shigenchishitsu1951.27.293

Jardim de Sá, E. F. (1984). Geologia da região de Seridó: reavaliação de dados. XI Simpósio de Geologia do Nordeste, Atas... 278-296. Natal: SBG.

Jardim de Sá, E. F., Hachspacher, P. C. (1980). Reconhecimento estrutural na borda noroeste do Cráton de São Francisco. XXXI Congresso Brasileiro de Geologia, Anais... 5, 2719-2731. Balneário Camboriú: SBG.

Jelinek, V. (1981). Characterization of the magnetic fabrics of rocks. Tectonophysics, 79(3-4), T63-T67. https://doi. org/10.1016/0040-1951(81)90110-4

Lima, M. M. C. (2013). Caracterização geoquímica, isotópica e geotectônica dos complexos Araticum e Arapiraca, faixa Sergipana-Alagoas. Dissertação (Mestrado). Recife: Centro de Tecnologia e Geociências - UFPE.

Lima, M. M. C., Silva, T. R., Ferreira, V. P., Silva, J. M. R. (2014). Metasedimentary rocks of the northern part of the Macururé domain, Sergipano Belt (northeastern Brazil): geochemical characterization of their protoliths and tectonic implications. Estudos Geológicos, 24, 89-107. http://dx.doi.org/10.18190/1980-8208/estudosgeologicos. v24n2p89-107

Medeiros, V. C., Santos, E. J. (1998). Folha Garanhuns (SC.24-Y-B): integração geológica. Recife. In: V. C. Medeiros. Relatório Interno. Recife: CPRM.
Mendes, V. A., Brito, M. F. L., Paiva, I. P. (2009). Programa Geologia do Brasil-PGB. Arapiraca. Folha SC.24-X-D. Estados de Alagoas, Pernambuco e Sergipe. Mapa Geológico. Recife: CPRM. 1 mapa, color, 112,37 cm × 69,42 cm. Escala $1: 250.000$.

Nery, N. R. N. (2016). Evolução tectono-metamórfica da cobertura deformada (quartzito Garanhuns) e de seu embasamento durante a orogênese brasiliana de uma área a SE da folha Venturosa. Dissertação (Mestrado). Recife: Centro de Tecnologia e Geociências - UFPE.

Neves, S. P. (2015). Constraints from zircon geochronology on the tectonic evolution of the Borborema Province (NE, Brasil): Widespread intracontinental Neoproterozoic reworking of a Paleoproterozoic accretionary orogen. Journal of South American Earth Sciences, 58, 150-164. https://doi. org/10.1016/j.jsames.2014.08.004

Neves, S. P., Araújo, A. M. B., Correia, P. B., Mariano, G. (2003). Magnetic fabrics in the Cabanas Granite (NE Brazil): interplay between emplacement and regional fabrics in a dextral transpressive regime. Journal of Structural Geology, 25(3), 441-453. https://doi.org/10.1016/ S0191-8141(02)00003-2

Neves, S. P., Bruguier, O., Bosch, D., Silva, J. M. R., Mariano, G. (2008). U-Pb ages of plutonic and metaplutonic rocks in southern Borborema Province (NE Brazil), timing of Brasiliano deformation and metamorphism. Journal of South American Earth Sciences, 25(3), 285-297. https://doi. org/10.1016/j.jsames.2007.06.003

Neves, S. P., Bruguier, O., Silva, J. M. R., Mariano, G., Silva Filho, A. F., Teixeira, C. M. L. (2015). From extension to shortening: dating the onset of the Brasiliano Orogeny in eastern Borborema Province (NE Brazil). Journal of South American Earth Sciences, 58, 238-256. https://doi. org/10.1016/j.jsames.2014.06.004

Neves, S. P., Mariano, G., Beltrão, B. B., Correia, P. B. (2005a). Emplacement and deformation of the Cachoeirinha pluton (Borborema province, NE Brazil) inferred through petrostructural studies: constraints on regional strain fields. Journal of South American Earth Sciences, 19(2), 127-141. https://doi.org/10.1016/j.jsames.2005.04.004

Neves, S. P., Monié, P., Bruguier, O., Silva, J. M. R. (2012). Geochronological, thermochronological and thermobarometric constraints on deformation, magmatism and thermal regimes in eastern Borborema Province (NE Brazil). Journal of South American Earth Sciences, 38, 129-146. https://doi. org/10.1016/j.jsames.2012.06.003 
Neves, S. P., Silva, J. M. R., Mariano, G. (2005b). Oblique lineations in orthogneisses and supracrustal rocks, vertical partitioning of strain in a hot crust (eastern Borborema Province, NE Brazil). Journal of Structural Geology, 27(8), 1513-1527. https://doi.org/10.1016/j.jsg.2005.02.002

Neves, S. P., Rangel da Silva, J. M., Bruguier, O. (2016). The transition zone between the Pernambuco-Alagoas Domain and the Sergipano Belt (Borborema Province, NE Brazil): Geochronological constraints on the ages of deposition, tectonic setting and metamorphism of metasedimentary rocks. Journal of South American Earth Sciences, 72, 266278. https://doi.org/10.1016/j.jsames.2016.09.010

Oliveira, E. P., Toteu, S. F., Araújo, M. N. C., Carvalho, M. J., Nascimento, R. S., Bueno, J. F., McNaughton, N., Basilici, G. (2006). Geologic correlation between the Neoproterozoic Sergipano belt (NE Brazil) and the Yaoundé schist belt (Cameroon, Africa). Journal of African Earth Sciences, 44(45), 470-478. https://doi.org/10.1016/j.jafrearsci.2005.11.014

Oliveira, E. P., Windley, B. F., Araújo, M. N. C. (2010). The Neoproterozoic Sergipano orogenic belt, NE Brazil: a complete plate tectonic cycle in western Gondwana. Precambrian Research, 181(1-4), 64-84. https://doi. org/10.1016/j.precamres.2010.05.014

Paterson, S. R., Vernon, R. H., Tobisch, O. T. (1989). A review of criteria for identification of magmatic and tectonic foliations in granitoids. Journal of Structural Geology, 11(3), 349-363. https://doi.org/10.1016/0191-8141(89)90074-6

Rochette, P. (1987). Magnetic susceptibility of the rock matrix related to magnetic fabric studies. Journal of Structural Geology, 9(8), 1015-1020. https://doi. org/10.1016/0191-8141(87)90009-5

Rochette, P., Jackson, M., Aubourg, C. (1992). Rock magnetism and interpretation of anisotropy of magnetic susceptibility. Reviews in Geophysics, 30(3), 209-226. https://doi.org/10.1029/92RG00733

Rosenberg, C. L. (2004). Shear zones and magma ascent: a model based on a review of the Tertiary magmatism in the Alps. Tectonics, 23(3), TC3002. https://doi. org/10.1029/2003TC001526

Sales das Neves, C. H. F., Ferreira, V. P., Neves, S. P. (2018). Caracterização litoquímica e geocronológica de granitos do Batólito Águas Belas-Canindé, no Domínio PernambucoAlagoas, na Província Borborema. Geologia USP. Série Cientifica, 18(4), 173-192. https://doi.org/10.11606/issn.23169095.v18-143981
Santos, E. J. (1996). Ensaio preliminar sobre terrenos e tectônica acrescionária na Província Borborema. XXXIX Congresso Brasileiro de Geologia, 6, 47-50. Anais... Salvador: SBG.

Santos, E. J., Nutman, A. P., Brito Neves, B. B. (2004). Idades SHRIMP U-Pb do Complexo Sertânia: implicações sobre a evolução tectônica da zona transversal, Província Borborema. Geologia USP. Série Científica, 4(1), 1-12. https://doi.org/10.5327/S1519-874x2004000100001

Sial, A. N. (1986). Granite types in northeast Brazil Current Knowledge. Revista Brasileira de Geociências, 16(1), 54-72. https://DOI.ORG/10.25249/0375-7536.19865472

Sial, A. N. (1990). Epidote-bearing calc-alkaline granitoids in Northeast Brazil. Revista Brasileira de Geociências, 20(1-4), 88-100.

Silva Filho, A. F., Gomes, H. A., Osako, L. S., Guimaraes, I. P., Luna, E. B. A. (2007). Folha Venturosa, Programa Geologia do Brasil, Internal Report. Convênio MME/UFPE.

Silva Filho, A. F., Guimarães, I. P., Santos, L., Armstrong, R., Van Schmus, W. R. (2016). Geochemistry, U-Pb geochronology, Sm-Nd and O isotopes of ca. $50 \mathrm{Ma}$ long Ediacaran high-K syn-collisional magmatism in the Pernambuco-Alagoas Domain, Borborema Province, NE Brazil. Journal of South American Earth Sciences, 68, 134154. https://doi.org/10.1016/j.jsames.2015.12.013

Silva Filho, A. F., Guimarães, I. P., Van Schmus, W. R. (2002). Crustal evolution of the Pernambuco-Alagoas complex, Borborema Province, NE Brazil: Nd isotopic data from Neoproterozoic granitoids. Gondwana Research, 5(2), 409-422. https://doi.org/10.1016/ S1342-937X(05)70732-2

Silva Filho, A. F., Guimarães, I. P., Van Schmus, W. R., Armstrong, R., Silva, J. M. R., Osako, L., Concentino, L. (2014). SHRIMP U-Pb zircon geochronology and Nd signatures of supracrustal sequences and orthogneisses constrain the Neoproterozoic evolution of the PernambucoAlagoas domain, southern part of Borborema Province, NE Brazil. International Journal of Earth Sciences, 103(8), 2155-2190. https://doi.org/10.1007/s00531-014-1035-4

Silva Filho, A. F., Guimarães, I. P., Ferreira, V. P., Armstrong, R., Sial, A. N. (2010). Ediacaran Águas Belas pluton, Northeastern Brazil: Evidence on age, emplacement and magma sources during Gondwana amalgamation. Gondwana Research, 17(4), 676-687. https://doi.org/10.1016/j. gr.2009.10.002 
Silva, L. C., Armstrong, R., Pimentel, M. M., Scandolara, J., Ramgrab, G., Wildner, W., Angelim, L. A. A., Vasconcelos, A. M., Rizzoto, G., Quadros, M. L. E. S., Sander, A., Rosas, A. L. Z. (2002). Reavaliação da evolução geológica em terrenos Precambrianos Brasileiros com base em novos dados U-Pb SHRIMP, Parte III: Provincias Borborema, Mantiqueira Meridional e Rio Negro-Jurema. Revista Brasileira de Geociências, 32(4), 529-544.

Silva, T. R., Ferreira, V. P., Lima, M. M. C. L., Sial, A. N. (2016). Two stage mantle-derived granitic rocks and the onset of the Brasiliano orogeny: Evidence from $\mathrm{Sr}, \mathrm{Nd}$, and O isotopes. Lithos, 264, 189-200. https://doi.org/10.1016/j. lithos.2016.08.030
Silva, T. R., Ferreira, V. P., Lima, M. M. C. L., Sial, A. N., Silva, J. M. R. (2015). Synkinematic emplacement of the magmatic epidote bearing Major Isidoro tonalite-granite batholith: Relicts of an Ediacaran continental arc in the Pernambuco e Alagoas domain, Borborema Province, NE Brazil. Journal of South American Earth Sciences, 64(Parte 1), 1-13. https://doi.org/10.1016/j.jsames.2015.09.002

Van Schmus, W. R., Oliveira E. P., Silva Filho, A. F., Toteu, S. F, Penaye, J., Guimarães, I. P. (2008). Proterozoic links between the Borborema province, NE Brazil and the Central African fold belt. Geological Society, London, Special Publications, 294(1), 69-99. https://doi.org/10.1144/SP294.5

Wones, D. R. (1989). Significance of the assemblage titanite + magnetite + quartz in granitic rocks. American Mineralogist, 74(7-8), 744-749. 